indicated linkage with autosomal genes such as those for blood-group membership.

A full account of the research will be published in the Annals of Eugenics, and further investigations are being undertaken.

Department of Genetics, J. B. S. Haldane.

University College, London, W.C.1.

${ }^{1}$ Penrose, Ann. Eugen., 6 (1935).

2 Bell, Treas. Human Inher., 4 (1936).

s Koller and Darlington, J.'Gen., 29, 159.

- Bernstein, Z. Abst. Vererb., 5 (1931).

- Fisher, Ann. Eugen. (in the press).

- Bell, Treas. Human Inher., 2 (1933).

7 Komai, "Pedigrees of Hered. Dis. and Abnormals, found in the Japanese Race". Kyoto (1934).

"Cockayne, "Inherited Abnormalities of the Skin and its Appendages". Oxford (1933).

'Siemens and Kohn, Z. Abst. Vererb., 38 (1925).

\section{Three Unpublished Letters of Charles Darwin}

Charles Darwin wrote several letters to William Benjamin Carpenter, five of which have been pub. lished in the "Life and Letters". The original MSS., eight in number, came to me on the death of my uncle, Joseph Estlin Carpenter, the last surviving son of William Benjamin, and I have presented them to Down House for preservation by the British Association.

A small misprint in the "Life and Letters", volume 2 , page 262, may now be corrected. The bottom line of that page gives the word "limbs", instead of "lambs" which obviously makes better sense.

The three unpublished letters are of some interest. The first is headed "Down, Bromley, Kent. June 17th", but the year is not given, though it may be surmised from the subject. The first two-thirds concern the recovery from illness of his daughter, and Darwin then continues:

"I have been of late sufficiently well pitched into to please anybody, about my Book. But I care very little, which I entirely and absolutely owe to the generous and kind support of a very few men. When I reflect, as I often do, that such men as Lyell, yourself, Hooker, and Huxley go a certain way with me nothing will persuade me that I am so wholly and egregiously in error as many of my reviewers think. Pray do not trouble yourself to answer this-my dear Carpenter."”

The second letter, dated April 21, is as follows:

"I read two days ago your article in the last Contemporary, and I must take the pleasure of expressing my extreme interest and admiration of it. This will cause you no trouble, as this most obviously requires no answer. The case of the 3 species of Protozoon (I forget the names) which apparently select differently sized grains of sand, \&c. is almost the (most ?) wonderful fact I ever heard of. One cannot believe that they have mental power enough to do so, and how any structure or kind of viscidity can lead to this result passes all understanding.

"Your views on the functions of the brain are also profoundly interesting, but I know not enough for my opinion to be worth a fraction of a farthing. I was, however, speculating on this subject, when writing on Expression, and came to the conclusion that when we actually tasted and thought of a sour taste, the same or some closely related part of the brain must be affected. Had I then known of your views I should have omitted the first alternative. I thank you heartily for the pleasure derived from your article and remain ...."

The article in the Contemporary Review is one entitled "On the hereditary transmission of acquired psychical habits" and will be found in the issue for April 1873 (volume 21, pages 779-795). This is the second of three articles; the first was published in January, the third in May.

"The case of the 3 species of Protozoon" is dis. cussed on p. 784. Carpenter wrote, "Here, then, is most distinct evidence of selective power; and the question forces itself upon us,-by what instru. mentality is it exercised ? . . . It seems ... difficult to conceive that so artificial an operation can be performed by a mechanism so simple".

The views on the functions of the brain to which Darwin also referred are given as follows on p. 791. ". . . there seems equal reason for believing that when Ideational changes in the Cerebrum give rise to Sensations, they do so by transmitting back to the Sensory Tract, through the descending fibres, some 'nervous modification' which those changes involve; thus producing in the Sensorium the same physical condition, whatever may be its nature, as that through which the Sensation was originally excited".

Darwin's third letter has a pathetic interest as it was written so shortly before his death. Dated February 13, 1882, from Down, it solicited Carpenter's vote on behalf of Mr. Albert Dicey's candidature for the Athenæum Club, and ends "I hope that you are fairly well. We are both growing old men, and I feel as old as Methuselah".

\section{G. D. Hale Carpenter.}

Oxford.

Feb. 1.

\section{Hæmocyanin in Heavy Water}

INFormation concerning the influence of heavy water on proteins is of interest from both a physio. logical and a physico-chemical point of view. One is inclined to assume that the observed effect of heavy water on living cells is to some extent due to a change in the protein molecules of the protoplasm. On the basis of the physico-chemical sensitivity of the protein molecule to changes in the environment, one is led to suspect that the replacement of ordinary water by heavy water as a solvent might cause dissociation or association of the molecules. The easiest and most direct way to detect effects of this kind is to submit the protein solutions to an ultra. centrifugal study.

As first material for investigation we have chosen the hæmocyanin contained in the blood of Helix pomatia. It has the advantage of being a protein of well-defined molecular weight showing marked disso. ciation-association reactions influenced by hydrogen ion concentration. A series of measurements of the sedimentation constant $s$ for solutions containing various amounts of heavy water gave the result shown in Fig. 1. The experimental values of $s$ corrected for the density and viscosity effects of the salt present ( 1 per cent $\mathrm{NaCl}$ ), and reduced to $20^{\circ} \mathrm{C}$., decrease continually with increasing $\mathrm{D}_{2} \mathrm{O}$ content (full curve). In 100 per cent $\mathrm{H}_{2} \mathrm{O}, s$ is about $100 \times 10^{-12}$; in 100 per cent $\mathrm{D}_{2} \mathrm{O}$ it is about $55 \times 10^{-13}$. If we recalculate the data assuming the change in 8 to be solely due to the increase in density and viscosity of the solvent, we obtain the values of the dotted 